\title{
Políticas públicas sobre aborto no Uruguai e no Brasil
}

Débora Karina Gonçalves Vaserino ${ }^{1}$

Patrícia Borba Marchetto ${ }^{2}$

\begin{abstract}
Resumo: O objetivo deste trabalho é analisar as políticas públicas do Uruguai sobre a questão do aborto, mais especificamente a Lei n. ${ }^{\circ}$ 18.987/2012 e o Decreto n..$^{\circ}$ 375/2012 e suas consequências. Além disso, faz-se uma análise das políticas públicas brasileiras sobre o tema e a atual discussão sobre a descriminalização do aborto na ADPF 442, bem como na criminalização de todas as hipóteses com a PEC 19/2015 do Senado e a PEC 181/15 da Câmara dos Deputados. Por questões metodológicas, esclarecemos que não se trata de um estudo comparativo, uma vez que não existe no Brasil nenhuma norma que regulamenta o aborto voluntário como no caso uruguaio e, portanto, não é possível realizar a comparação. Esta pesquisa é de revisão da literatura, com a exposição da política do Uruguai sobre o tema do aborto e a questão no Brasil atualmente para, ao final, tecer conclusões para aprimoramento das políticas públicas brasileiras com base na experiência bem-sucedida uruguaia.
\end{abstract}

Palavras-chave: política pública; saúde; aborto; descriminalização; mortalidade materna.

\section{Abortion public policies in Uruguay and Brazil}

Abstract: The purpose of this paper is to analyze Uruguay's public policies on abortion, specifically Law N. ${ }^{\circ}$ 18.987/2012 and Decree . $^{\circ}$ 375/2012 and its consequences. In addition, an analysis of Brazilian public policies on the subject and the current discussion on the decriminalization of abortion in ADPF 442, as well as in the criminalization of all the hypotheses with the PEC 19/2015 of the Senate and the PEC 181/15 of the Chamber of Deputies. For methodological reasons, we clarify that this is not a comparative study, since there is no rule in Brazil that regulates voluntary abortion as in the Uruguayan case and therefore, it is not possible to make the comparison. This research is a review of the literature, with the exposition of Uruguayan policy on abortion and the issue in Brazil currently, in order to draw conclusions for the improvement of Brazilian public policies based on the successful Uruguayan experience.

Keywords: public policy; health; abortion; decriminalization; maternal mortality.

\section{Introdução}

Ao chegar à presidência do Uruguai em 2010, José Alberto Mujica Cordano tinha a responsabilidade de dar continuidade ao processo de recuperação da crise do corralito argentino que afundou o país. Tratou-se de medida imposta pelo governo que congelou os depósitos nas poupanças e contas correntes e estabeleceu limites semanais para a retirada de fundos durante a crise econômica da Argentina em 2001, com intuito de impedir a quebra do sistema financeiro.

Economicamente, o país se recuperava de fuga de capitais, população em situação de pobreza, colapso do sistema financeiro, além de dívida com o FMI. Pepe Mujica, como era popularmente conhecido, não só se destacou no plano econômico, como também por sua política de esquerda, que priorizava a universalização das políticas públicas junto à sociedade e a ampliação da participação popular nos mecanismos institucionais de consulta democrática.

Nascido em 20 de maio de 1935, Pepe Mujica foi o mais moderno e ousado Presidente do Uruguai e concretizou grandes mudanças políticas entre 2010 e 2015. De posicionamento liberal em relação aos costumes, enfrentou a ditadura militar uruguaia que assolou o país entre 1973 e 1985. Figura importante na redemocratização do país, participou (e participa, diga-se de passagem) 
da vida política com apoio das massas populares. Foi durante seu governo que o poder legislativo do Uruguai aprovou a Lei do Aborto (Lei n. ${ }^{\circ}$ 18.987/2012), objeto do presente estudo comparativo, por ser a principal política pública sobre direitos reprodutivos das mulheres.

Do outro lado da comparação, temos o Brasil, que em 2019 ainda considera o aborto crime (artigo 124 do Código Penal) e, portanto, edita políticas públicas que não colocam efetivamente em prática direitos constitucionalmente garantidos no que diz respeito à autonomia e liberdade individual da mulher. Recentemente, em agosto de 2018, no âmbito da ADPF 442, foi discutida no Supremo Tribunal Federal por meio de audiência pública a descriminalização do aborto. Contudo, a referida Arguição de Descumprimento de Preceito Fundamental ainda aguarda decisão.

Destacam-se no cenário nacional a Política Nacional de Atenção Integral à Saúde da Mulher e a Rede Cegonha, dentro do Sistema Único de Saúde, que são as principais políticas de governo para atenção à mulher no que diz respeito ao planejamento reprodutivo e ao nascimento seguro. Ainda para situar o leitor nesta discussão, o Brasil possui hoje, após as eleições de 2018, governo de vertente conservadora e com ideais políticos de direita. Neste diapasão, não é prioridade discutir e implantar políticas públicas que versem sobre a questão do aborto e não há perspectiva de que haja sua descriminalização.

Ao contrário do Uruguai dos últimos anos, o legislativo brasileiro caminha no sentido de tornar cada vez mais restrito os direitos da mulher sobre seu próprio corpo. No dia 12 de fevereiro de 2019, por maioria de votos, o Senado Federal aprovou o desarquivamento da Proposta de Emenda à Constituição (PEC) 29/2015, também denominada pelo senador Magno Malta de "PEC da vida". A referida proposta visa proibir o aborto em qualquer situação, inclusive nas que são autorizadas hoje pelo ordenamento jurídico: gravidez decorrente de violência sexual, que ofereça risco de vida à mãe ou com feto anencéfalo. Tramita na Câmara dos Deputados a PEC 181/2015, que propõe alterar o artigo $5^{\circ}$ da Constituição Federal, incluindo que a inviolabilidade do direito à vida é desde a concepção e, consequentemente, proibindo o aborto em qualquer hipótese.

Sendo assim, o objetivo deste trabalho é analisar as políticas públicas do Uruguai sobre a questão do aborto, mais especificamente a Lei n. ${ }^{\circ}$ 18.987/2012 e suas consequências. Além disso, faz-se uma análise das políticas públicas brasileiras sobre o tema. Por questões metodológicas, esclarecemos que não se trata de um estudo comparativo, uma vez que não existe no Brasil nenhuma norma que regulamente o aborto voluntário como no caso uruguaio e, portanto, não é possível realizar a comparação. Esta pesquisa é de revisão da literatura, com a exposição da política do Uruguai sobre o tema do aborto e a questão no Brasil atualmente para, ao final, tecer conclusões para aprimoramento das políticas públicas brasileiras com base na experiência bem-sucedida uruguaia.

\section{Discussão}

Lei n. ${ }^{\circ} 18.987 / 2012$ do Uruguai

O Uruguai, assim como a maioria dos países da América do Sul - inclusive o Brasil -, passou por um período de ditadura. Na década de 1960 houve um processo de deterioração social e política, com aumento do número de conflitos com grupos de resistência, incluindo luta armada de guerrilhas urbanas. 
Nas eleições de 1971 houve um empate político que levou à presidência Juan Mará Bordaberry, representante dos ruralistas e com orientações ideológicas antidemocráticas. Neste mesmo ano, houve rompimento da ordem institucional que culminou em um golpe militar. Primeiro a insubordinação militar, na qual se acatou a institucionalização dos militares como protagonistas no governo. Em seguida, as Forças Armadas e os generais decidiram fechar o Parlamento por tempo indeterminado. O governo então anuncia em cadeia nacional de rádio o Decreto n. ${ }^{\circ} 646$, que acabou por dissolver as Câmaras de senadores e representantes. Nesse contexto,

O desenlace da crise uruguaia, expresso no golpe de Estado, adquiriu um significado que
transcendia os limites do país. Dessa vez, como em poucas oportunidades, o Uruguai
foi assimilado à pulsação dramática da América Latina e aparentemente enterrou sua
"singularidade", que tantas vezes havia proclamado. Em apenas alguns anos, entre 1973
e 1976 , o Cone Sul ficou por completo nas mãos de ditaduras militares ("a outra Santa
Aliança", segundo dizia o jornalista Carlos Quijano), que responderam a parecidos
estímulos externos, implementaram políticas públicas de similar teor e, ainda que levando
em conta importantes diferenças, praticaram a mesma sistemática violação dos direitos
humanos. De modo paradoxal, essa forma de vinculação do Uruguai à região ("latino-
americanização", chegou-se a dizer) foi simultânea com um formidável processo de
transformações mundiais do qual o país permaneceu relativamente isolado. (HARGAIN,
2006, n.p.)

Apesar do fechamento do Congresso, houve a tentativa de reforma constitucional com o pretexto de reafirmar princípios republicanos-democráticos do novo governo, que seria feito pelo Conselho de Estado, criado para substituir as funções legislativas. Também foi criado o Conselho da Nação, órgão do poder Executivo constituído por ex-presidentes da República, membros da Suprema Corte de Justiça, figuras de grande relevância nacional e por membros das Forças Armadas.

Em 1976 o governo de Bordaberry desagradou as Forças Armadas ao apresentar novas medidas de organização, as quais envolviam a destituição de partidos políticos, a soberania nacional exercida mediante plebiscitos ou pelo recém-criado Conselho da Nação e a eliminação da democracia representativa, sendo o Presidente da República eleito por um período de cinco anos pelo Conselho da Nação. Os militares recusaram a proposta, por entenderem que acabar com os partidos políticos seria arriscado. Diante da recusa, iniciou-se o conflito entre Juan Maria e o alto escalão das Forças Armadas, que terminou com destituição de Bordaberry da Presidência.

Alberto Demicheli, vice-presidente, assumiu o poder após ser indicado pelo Conselho. Foi a fase de maior controle estatal da história da ditadura uruguaia, com a criação dos atos institucionais um e dois, que instituiu o toque de recolher e a proibição do direito a greves.

A partir do plebiscito de 1980 iniciou-se o período de transição, pois a recusa pela maioria da população favoreceu a abertura democrática. Neste plebiscito de 30 de novembro de 1980, o povo rechaçou o projeto de reforma constitucional proposto pelo regime com objetivo de legitimar o governo de fato, iniciando o processo de abertura política.

No plano econômico, o Uruguai sofreu com forte ajuste recessivo, inclusive assinando carta de intenção com o FMI em condições difíceis em vários planos. Houve aumento significativo da taxa de desemprego, além de endividamento interno e redução da exportação.

A gigantesca concentração popular de 27 de novembro de 1983 - talvez a maior de toda a história política do país - marcou o ponto de máxima confluência entre a mobilização social e o consenso partidário por trás de um programa intransigentemente democrático. 


\begin{abstract}
Daí por diante, a esquerda política ficou definitivamente integrada e acreditada na frente de oposição, legalizada de fato, em que pese a permanência da proscrição imposta pelo regime. No entanto, foi a partir daí que a "ditadura transicional" começou a viver uma segunda etapa, assinalada pela vontade de acordo entre militares e políticos, e orientada crescentemente em direção à dinâmica da negociação, o que devolvia o timão aos partidos. Essa vocação negociadora desembocou em três resultados de grande interconexão: relativizou a pressão da mobilização social, trouxe as eleições mais cedo para a dinâmica política (diante das eleições gerais previstas para novembro de 1984) e ajustou a saída para um "pacto" entre os militares e a maioria dos partidos políticos. (HARGAIN, 2006, n.p.)
\end{abstract}

Em março de 1985 o Uruguai ingressou em uma etapa de transição efetiva rumo a sua redemocratização, após as eleições de 1984. Houve anistia aos presos políticos, responsabilização das violações aos direitos humanos durante a ditadura e regularização das instituições de um Estado de Direito.

O quadro de crise econômica do Uruguai era grave, o país estava mergulhado em uma profunda crise social e com altas taxas de desemprego. Esta situação começou a mudar em 2004, com a vitória política de Tabaré Vázquez no primeiro turno das eleições nacionais. Sua vitória marcou o fim de uma hegemonia de 175 anos de governos colorados, nacionalistas ou de ditaduras cívico-militares. Não só foi eleito um Presidente da República de esquerda, como também a maioria em ambas as Câmaras Legislativas, o que marcou a vitória da esquerda no campo político. A prioridade de sua administração foi a distribuição de renda através de políticas sociais governamentais.

O presidente implantou o Plano de Atenção Nacional de Emergência Social (Pasen), que foi responsável por distribuir alimentos e dinheiro às famílias carentes, atingindo aproximadamente duzentas mil pessoas que viviam abaixo da linha da pobreza. Em 2007, o Uruguai se tornou a primeira nação latino-americana a legalizar a união civil entre pessoas do mesmo sexo. Em 2009, o legislativo aprovou a adoção de crianças por casais gays; no mesmo ano, a eutanásia foi aceita quando o paciente expressar sua vontade de realizar o procedimento.

Chegando à presidência do Uruguai em 2010, José Alberto Mujica Cordano foi eleito em segundo turno com cerca de $52 \%$ dos votos. As características mais marcantes do mandato de Pepe Mujica, como era popularmente conhecido, foram os avanços no campo dos costumes.

Em 2011, senadores da Frente Ampla, partido do presidente eleito, apresentaram projeto de lei que previa a legalização da interrupção voluntária da gravidez. O projeto foi aprovado no Senado por dezessete votos a favor e quatorze contrários. Seguiu, então, para votação na Câmara de Deputados que, em 2012, também o aprovou. A votação na segunda Casa foi apertada, sendo cinquenta deputados a favor e quarenta e nove contra. O Uruguai, então, foi o segundo país da América Latina (Cuba foi o primeiro) a legalizar o aborto nas primeiras doze semanas de gestação ao promulgar a Ley 18.987/2012 ("Ley de la Interrupcion Voluntaria del Embarazo" ou "IVE”). O prazo se estende às primeiras quatorze semanas nos casos de estupro e pode ser maior no caso de risco de morte para a gestante ou anomalias fetais incompatíveis com a vida.

A aprovação da lei de descriminalização do aborto foi essencial para a continuidade das políticas públicas na área da saúde com foco na redução de riscos e com objetivo de reduzir o número de mortes de mulheres ou complicações causadas por abortos clandestinos. A principal política pública sobre aborto no Uruguai se deu com a regulamentação da lei sobre interrupção da gravidez através do Decreto 375/2012 (“Regulamentacion de La Ley de IVE”), publicado em 29 de novembro de 2012. 
$\mathrm{O}$ artigo $2^{\circ}$ do referido Decreto estabelece os princípios de atuação das instituições médicas e de pessoal nos procedimentos regulados pela Lei do Aborto. São eles: a confidencialidade, o consentimento informado e o respeito à autonomia da vontade da mulher. Isto implica que o pessoal de saúde deve abster-se de impor seus valores e crenças, bem como suas visões filosóficas, tendo que agir e informar à mulher que deseja interromper uma gravidez de acordo com as evidências científicas disponíveis. Além disso, caso a mulher beneficiária do Seguro Nacional de Saúde considerar que o prestador de saúde da qual é afiliada não gera confiança suficiente, pode solicitar mudança de profissional ao Conselho Nacional de Saúde.

Em relação aos requisitos para solicitar a interrupção voluntária da gestação estão apenas a nacionalidade uruguaia, natural ou legal, bem como mulheres estrangeiras com mais de um ano de residência no país. Sobre o procedimento, a mulher deve comparecer a hospital credenciado ao Sistema Nacional Integrado de Saúde solicitando uma consulta médica e manifestar seu interesse de interromper a gravidez ao médico, citando qualquer uma das razões estabelecidas na Lei $\mathrm{n}^{\circ}$ 18.987/12. Sobre tais requisitos, são eles as circunstâncias decorrentes das condições em que ocorreu a concepção: situações de penúria econômica, social, familiar ou de idade que, na opinião da gestante, impedem que prossiga com o andamento da gravidez.

No mesmo dia ou no dia seguinte, o médico providenciará uma consulta com uma equipe interdisciplinar integrada por pelo menos três profissionais, devendo ser um ginecologista, um da área de saúde psíquica e um na área social. Esta equipe, através de atuação em conjunto, deve informar à mulher o estabelecido na lei, as características do procedimento da interrupção da gravidez e dos riscos inerentes a essa prática. Além disso, informará sobre as alternativas ao aborto induzido, como programas de apoio econômico e social disponíveis ou, ainda, a possibilidade de adoção.

Em geral, o procedimento estabelecido pela Lei do Aborto tem por objetivo oferecer um campo de apoio psicológico e social para as mulheres, para ajudá-las a superar possíveis causas do desejo de terminar a gravidez, bem como garantir que elas tenham todas as informações para tomada de decisão consciente e responsável. Após o encontro com a equipe multidisciplinar, a mulher terá um período mínimo de cinco dias para reflexão, após os quais ela poderá ratificar seu desejo de interromper a gestação. A ratificação da solicitante será expressa mediante consentimento informado, que deverá ser por escrito e assinado pela mulher e, após, será incorporada ao seu prontuário médico. Neste caso, o procedimento para realização do aborto voluntário será imediatamente coordenado por um ginecologista.

O ginecologista, em razão da relação médico-paciente, será o único a determinar o tipo de procedimento a ser seguido para prosseguir com a interrupção voluntária da gravidez, com base em evidências científicas que visem a redução dos riscos no caso concreto, as condições de cada paciente, bem como as orientações emitidas pelo Ministério da Saúde Pública.

O artigo 12 do Decreto 375/2012 prevê princípios específicos a serem seguidos pela equipe interdisciplinar, para além dos já previstos no artigo $2^{\circ}$. Em primeiro lugar, há previsão de que a equipe deve atuar dentro do contexto de proteção à saúde integral da mulher, sendo todos os aconselhamentos neste sentido. Em segundo lugar, a equipe deve executar as ações garantindo a confidencialidade e tratamento privado de todas as informações geradas durante a entrevista, observando o disposto nos regulamentos vigentes acerca de sigilo profissional. Em terceiro lugar, reitera-se 
a preocupação com a não imposição de convicções filosóficas ou pessoais dos membros da equipe sobre as mulheres, estando expressamente determinado que os profissionais devam abster-se de qualquer juízo de valor sobre a posição que a requerente adotar.

Estão também previstos no Decreto cinco deveres aos quais vinculam os profissionais da equipe. Eles devem orientar e aconselhar as mulheres sobre os meios apropriados para prevenir futuras gestações e como acessá-los, bem como sobre programas de planejamento familiar existentes. Devem realizar, caso haja consentimento expresso da mulher neste caso, entrevista com o pai; a equipe, contudo, não deve induzi-la ou influenciá-la a dar este consentimento. O terceiro dever diz sobre garantir, no âmbito de sua competência, que a decisão da mulher não seja viciada por pressão de terceiros, seja ela de continuar ou interromper a gravidez. Em quarto lugar, a equipe tem o dever de cumprir o protocolo de ação organizado pelo Ministério da Saúde Pública. Por fim, deve abster-se de assumir a função de autorizar ou negar a interrupção da gravidez. Em outras palavras, isto significa que a equipe tem o dever de não se pronunciar sobre a decisão da mulher.

Sobre o dever de entrevistar o pai, o artigo 14 prevê que será designado dia e horário específico para este fim, além de que esta entrevista tem o único propósito de informar o estabelecido na Lei do Aborto e no Decreto, além de cumprir as diretrizes impostas pelo Ministério da Saúde Pública. Todavia, em nenhuma hipótese, essa entrevista pode atrasar ou interromper o processo iniciado pela requerente. Além disso, a mulher deve expressamente definir as informações que poderão ser abordadas e informá-las à equipe, sendo a última obrigada a atuar dentro dos limites do sigilo profissional.

O Decreto prevê uma exceção especial à regra do consentimento informado, previsto no artigo $6^{\circ}$ da Lei do Aborto. A regra é de que, em todos os casos, as mulheres devem dar seu consentimento informado expressamente e por escrito. Contudo, no caso da gravidez implicar um grave risco à saúde da mulher e por seu estado de saúde ela não puder fornecer seu consentimento para realização da interrupção da gravidez, este será dado por seus familiares na ordem prevista no artigo 24, alínea c do Decreto n. ${ }^{\circ}$ 274/2010 (cônjuge ou concubino e, após, parente por consanguinidade ou afinidade mais próximo). Ainda, no caso de emergência médica, a intervenção prosseguirá de acordo com o que o médico assistente considere mais apropriado para preservar a saúde ou a vida da paciente.

A política pública adotada pelo Uruguai para tratar da interrupção voluntária da gravidez prevê a criação de uma Comissão dentro do Ministério da Saúde Pública para ditar as regras de seu funcionamento. Essa comissão será composta por um representante do Ministério da Saúde Pública, um do Departamento de Obstetrícia e Ginecologia da Faculdade de Medicina, um da Cátedra de Neonatologia da Faculdade de Medicina e um do Conselho Nacional de Saúde. Em conjunto, estes profissionais serão responsáveis por analisar as solicitações de interrupção de gravidez em casos de malformações incompatíveis com a vida extrauterina. Uma vez que haja pronunciamento positivo da comissão, o médico, com o consentimento informado da mulher e de acordo com as circunstâncias e condições médicas, providenciará a coordenação necessária para proceder à interrupção da gravidez.

No caso da gravidez ser produto de violência sexual, basta que seja apresentada a queixa-crime ao médico assistente, que a anexará no prontuário médico da paciente. Nesta hipótese, também 
é necessário o consentimento escrito da mulher que deseja interromper a gravidez. Destaca-se neste ponto o cuidado que o artigo 18 possui para com as vítimas de abusos, pois está expressamente previsto que se deve evitar qualquer ato que implique uma revitimização das mulheres. Logo, as mulheres são reafirmadas como sujeito de direitos, plenamente capazes, respeitando a autodeterminação e vontade próprias.

Todas as instituições de saúde do Sistema Integrado Nacional de Saúde são obrigadas a cumprir as disposições previstas pelo Decreto 375/2012 e pela Lei do Aborto, além do dever de fornecer condições técnico-profissionais e administrativas necessárias para o acesso das usuárias aos procedimentos, respeitando sempre os prazos estabelecidos e de acordo com todas as diretrizes e regulamentos emitidos pelo Ministério da Saúde Pública. Somente podem escusar-se do cumprimento dessas obrigações as instituições que antes da entrada em vigor da lei n. ${ }^{\circ}$ 18.987/12 declararam objeção de ideologia e apresentaram pedido para não prosseguir interrupções voluntárias de gravidez perante o Conselho Nacional de Saúde. Contudo, estas instituições não podem recusar a realizar interrupções quando a gravidez envolve sério risco para a saúde da mulher.

Além disso, caso a paciente solicite a interrupção da gravidez em alguma instituição que tenha declarado objeção de ideologia, esta deve executar todos os procedimentos anteriores ao ato médico que implica a interrupção da gravidez. Em seguida, deverá encaminhar a usuária para instituição que forneça o serviço.

A objeção de ideologia somente é válida para pessoas jurídicas, mais especificamente instituições médicas. Não se confunde com a objeção de consciência, que é direito das pessoas físicas. Em qualquer caso, as instituições têm o dever de respeitar a liberdade de consciência dos seus dependentes, inclusive a independência da consciência moral e cívica do seu pessoal subordinado. O exercício da objeção de consciência obriga o médico a obter pessoalmente ao paciente outro médico, a fim de garantir a continuidade da atenção imediata ao paciente.

Não se permite exercer o direito à objeção de consciência o pessoal administrativo, operacional ou outro que não possua intervenção direta no respectivo ato médico. Nenhuma objeção de consciência pode ser invocada em atos posteriores à realização da interrupção da gravidez. O Decreto prevê uma forma específica para realização da objeção de consciência, sendo válidas apenas as que seguirem o procedimento pré-estabelecido. Além disso, a qualquer momento o objetor de consciência pode revogar sua objeção.

Outro ponto importante foi a cobertura integral do procedimento pelo poder público. As instituições autorizadas devem celebrar acordos e contratos para que as usuárias que solicitem a interrupção voluntária da gravidez não tenham nenhum custo para realização da prática médica. Com o Estado se encarregando de todas as despesas, há garantia dos direitos das mulheres.

$\mathrm{O}$ consentimento informado de pacientes menores de idade está regulamentado no artigo 37. De acordo com a idade da menina ou adolescente, o médico ou equipe interdisciplinar devem analisar o consentimento juntamente com a concordância dos pais ou outros adultos responsáveis de confiança da solicitante, respeitando em todos os casos a autonomia progressiva das adolescentes. Caso considere-se que a menor pode fornecer consentimento válido, só poderão notificar os pais ou representantes legais caso seja formalmente e expressamente liberado pela adolescente o dever de manter sigilo profissional, caso que deve ser registrado no prontuário. Ao revés, caso seja entendi- 
do que falta maturidade da menor de conceder um consentimento válido para o término da gravidez, devem os profissionais notificar os pais ou responsáveis para que eles forneçam assentimento.

Nota-se, por fim, a preocupação com a garantia de sigilo da mulher, em todos os atos. Nas informações que as instituições enviam para o Ministério da Saúde Pública não são permitidos quaisquer dados que, direta ou indiretamente, permitam a identificação da solicitante do aborto, sempre preservando seu anonimato.

Ao longo destes anos, desde a vigência da Lei do Aborto, é possível constatar, estatisticamente, que a política pública adotada pelo Uruguai após a descriminalização do aborto gerou progresso dos dados de mortalidade materna associada à interrupção voluntária da gravidez. Segundo o Ministério da Saúde, nos últimos anos foi registrada apenas uma ou nenhuma morte por ano, apesar das dificuldades no acesso aos métodos no interior do país (MINISTÉRIO DA SAÚDE DO URUGUAI, 2017, n.p.).

O número de mulheres que procurou o acesso à interrupção voluntária da gravidez aumentou em 2016 em relação a 2015: foram 9.719 casos, 350 a mais. Apesar deste aumento, observou-se que $6 \%$ das mulheres decidem continuar a gravidez após procurar o serviço médico e realizar o aconselhamento com a equipe multidisciplinar (MINISTÉRIO DA SAÚDE DO URUGUAI, 2017, n.p.).

Logo, é incontestável que a Lei do Aborto, bem como o Decreto que a regulamentou e instituiu políticas públicas na área da saúde foram eficientes no seu objetivo: diminuir o número de mortes de mulheres pela prática do aborto inseguro.

No Brasil, a situação é completamente diferente. De acordo com o Ministério da Saúde durante a Audiência Pública na ADPF 442, em que se discute a descriminalização do aborto no país, foi levado a conhecimento do STF que os procedimentos inseguros de interrupção voluntária da gravidez levam à hospitalização de mais de 250 mil mulheres por ano, causando a morte de 203 mulheres em 2016. Nos últimos 10 anos, foram duas mil mortes maternas por este motivo. Além disso, a criminalização do aborto não impede que mais de um milhão de procedimentos sejam realizados por ano (MINISTÉRIO DA SAÚDE DO BRASIL, 2018, n.p.).

A principal política pública do Brasil que aborda a questão do aborto é a Rede Cegonha, de competência do Ministério da Saúde dentro do SUS, projeto instituído em 2011. Além disso, temos a Política Nacional de Atenção Integral à Saúde da Mulher, publicada em 2004, que estabelece princípios e diretrizes na atenção à saúde da mulher.

\section{O Brasil e a regulamentação do aborto}

O Brasil regula a possibilidade de interrupção da gravidez através do artigo 124 do Código Penal, que prescreve: "Provocar aborto em si mesma ou consentir que outrem lho provoque: Pena - detenção, de 1 (um) a 3 (três) anos.” (BRASIL, 1940, n.p.). Portanto, apesar das hipóteses legais permissivas, a regra é a não autorização da interrupção voluntária da gestação por ser tutelada como crime. É a partir desta lógica punitiva da interrupção voluntária da gravidez que são orientadas as políticas públicas da saúde da mulher.

A Política Nacional de Atenção Integral à Saúde da Mulher é um documento elaborado pelo Ministério da Saúde, publicado em 2004 em parceria com diversos setores da sociedade e reflete o 
compromisso com a implementação de ações da saúde que contribuam para a garantia dos direitos humanos das mulheres e reduzam a morbimortalidade por causas preveníveis e evitáveis. Este documento institui princípios e diretrizes elaborados pela Secretaria de Atenção à Saúde do Departamento de Ações Programáticas Estratégicas.

Através de um enfoque de gênero, busca consolidar os avanços no campo dos direitos sexuais e reprodutivos das mulheres, com ênfase na melhoria da atenção obstétrica, no planejamento familiar, na atenção ao abortamento inseguro e no combate à violência doméstica e sexual. O objetivo é ampliar as ações para grupos historicamente alijados das políticas públicas brasileiras.

O documento traz breve histórico da evolução das políticas de atenção à saúde da mulher no Brasil, que começou nas primeiras décadas do século XX e eram demandas limitadas à gravidez e ao parto. Os programas dessa época eram baseados no papel social da mulher: mãe e doméstica, responsável pela criação dos filhos e cuidado com a saúde dos demais familiares. Estes programas foram criticados pela lógica reducionista com que tratavam a mulher, uma vez que só eram assistidas no ciclo gravídico-puerperal.

Após reivindicação de mulheres organizadas e amparadas pelo movimento feminista, foi proposta nova avaliação, elaboração e execução de políticas públicas de saúde da mulher que atendessem às mudanças das relações sociais entre homens e mulheres. Em 1984, foi criado o Programa de Assistência Integral à Saúde da Mulher (PAISM) pelo Ministério da Saúde, que marcou esta ruptura conceitual com os princípios norteadores da política de saúde das mulheres.

O PAISM incorporou como princípios e diretrizes as propostas de descentralização, hierarquização e regionalização dos serviços, bem como a integralidade e a eqüidade da atenção, num período em que, paralelamente, no âmbito do Movimento Sanitário, se concebia o arcabouço conceitual que embasaria a formulação do Sistema Único de Saúde (SUS). O novo programa para a saúde da mulher incluía ações educativas, preventivas, de diagnóstico, tratamento e recuperação, englobando a assistência à mulher em clínica ginecológica, no pré-natal, parto e puerpério, no climatério, em planejamento familiar, DST, câncer de colo de útero e de mama, além de outras necessidades identificadas a partir do perfil populacional das mulheres. O processo de construção do SUS tem grande influência sobre a implementação do PAISM. O SUS vem sendo implementado com base nos princípios e diretrizes contidos na legislação básica: Constituição de 1988, Lei n. ${ }^{\circ}$ 8.080 e Lei n. ${ }^{\circ}$ 8.142, Normas Operacionais Básicas (NOB) e Normas Operacionais de Assistência à Saúde (NOAS), editadas pelo Ministério da Saúde. Particularmente com a implementação da NOB 96, consolida-se o processo de municipalização das ações e serviços em todo o País. A municipalização da gestão do SUS vem se constituindo num espaço privilegiado de reorganização das ações e dos serviços básicos, entre os quais se colocam as ações e os serviços de atenção à saúde da mulher, integrados ao sistema e seguindo suas diretrizes. (MINISTÉRIO DA SAÚDE DO BRASIL, 2004, p. 16)

Ainda sobre a Política Nacional de Atenção Integral à Saúde da Mulher, foram apresentados dados sobre a situação demográfica do Brasil à época, demonstrando a realidade multifacetada e sua complexidade para formulação de políticas públicas. Em seguida, foi apresentado breve diagnóstico da situação da saúde da mulher no Brasil que trata, em pouco mais de uma página, sobre o abortamento em condições de risco.

A partir de uma breve exposição dos fatos, foi reconhecido que a situação de ilegalidade na qual o aborto é realizado no Brasil afeta a existência de estatísticas confiáveis que subsidiem a implementação de políticas públicas mais precisas sobre o tema. Além disso, o aborto realizado 
em condições de risco é geralmente acompanhado de complicações severas e que figura entre as principais causas de morte materna, além de ser causa de discriminação e violência institucional contra mulheres nos serviços de saúde.

A violência configura-se "no retardo do atendimento, na falta de interesse das equipes em escutar e orientar as mulheres ou mesmo na discriminação explícita com palavras e atitudes condenatórias e preconceituosas" (MINISTÉRIO DA SAÚDE DO BRASIL, 2004, pg. 31). Por fim, há o reconhecimento de que nem todas as mulheres buscam os serviços de saúde por ocasião de um aborto, o que leva a um registro não condizente com a realidade brasileira e no prejuízo que a falta de dados gera para elaboração de políticas públicas que visem prevenir esta situação.

O documento segue tratando sobre outros problemas de saúde ou especificidades que atingem as mulheres no Brasil, como a precariedade da assistência em anticoncepção, as DST's, a violência doméstica e sexual, a saúde de mulheres adolescentes, a saúde da mulher no climatério/menopausa, saúde mental e gênero, doenças crônico-degenerativas e câncer ginecológico, saúde das mulheres lésbicas, negras, indígenas, residentes e trabalhadoras na área rural e em situação de prisão.

Após a exposição dos problemas, há a apresentação de princípios para a Política Nacional de Atenção Integral à Saúde da Mulher baseados na humanização e na qualidade da atenção em saúde. Em seguida são apresentadas as diretrizes e objetivos gerais da Política para, então, chegar aos princípios específicos e estratégias na área. Sobre o abortamento inseguro, foi apresentado o seguinte:

Promover a atenção obstétrica e neonatal, qualificada e humanizada, incluindo a assistência ao abortamento em condições inseguras, para mulheres e adolescentes: construir, em parceria com outros atores, um Pacto Nacional pela Redução da Mortalidade Materna e Neonatal; qualificar a assistência obstétrica e neonatal nos estados e municípios; organizar rede de serviços de atenção obstétrica e neonatal, garantindo atendimento à gestante de alto risco e em situações de urgência/emergência, incluindo mecanismos de referência e contra-referência; fortalecer o sistema de formação/capacitação de pessoal na área de assistência obstétrica e neonatal; elaborar e/ou revisar, imprimir e distribuir material técnico e educativo; qualificar e humanizar a atenção à mulher em situação de abortamento; apoiar a expansão da rede laboratorial; garantir a oferta de ácido fólico e sulfato ferroso para todas as gestantes; melhorar a informação sobre a magnitude e tendência da mortalidade materna. (MINISTÉRIO DA SAÚDE DO BRASIL, 2004, p. 69)

O documento analisado é, ainda hoje, decorrido aproximadamente quinze anos de sua publicação, a principal política pública brasileira para o tratamento da questão do aborto inseguro. Além disso, notamos que é formado por medidas essencialmente abstratas e ideais, que não cumprem a função de solucionar de maneira efetiva o problema, que leva a morte de centenas de mulheres por ano no Brasil.

No mesmo sentido da Política Nacional de Atenção Integral à Saúde da Mulher, existe a Rede Cegonha, instituída pela portaria n. ${ }^{\circ}$ 1.459/2011 do Ministério da Saúde, é outra política pública adotada pelo Governo Federal que possui como objetivo a redução da mortalidade materna e neonatal. Trata-se de rede de cuidados que assegura às mulheres o direito ao planejamento reprodutivo, a atenção humanizada à gravidez, parto, abortamento e puerpério.

Trata-se de importante estratégia política do SUS para cuidados com mulheres grávidas e com as crianças nos primeiros anos de vida. Apesar de constar no preâmbulo da portaria que a institui que os indicadores de mortalidade materna no Brasil são elevados em relação a países desen- 
volvidos e configurar entre os objetivos a assistência humanizada ao abortamento, não há sequer a palavra "aborto" ou "abortamento" no texto legal.

Sobre o debate acerca da descriminalização do aborto até a $12^{\mathrm{a}}$ semana de gestação no Brasil, tramita no Supremo Tribunal Federal a ADPF 442. A tese desta Ação de Descumprimento de Preceito Fundamental (ADPF) é que as razões jurídicas que moveram a criminalização do aborto pelo Código Penal de 1940 não se sustentam porque violam os preceitos fundamentais da dignidade da pessoa humana, da cidadania, da não discriminação, da inviolabilidade da vida, da liberdade, da igualdade, da proibição de tortura ou tratamento desumano ou degradante, da saúde e do planejamento familiar de mulheres, adolescentes e meninas (Constituição Federal, art. $1^{\circ}$, incisos I e II; art. $3^{\circ}$, inciso IV; art. $5^{\circ}$, caput e incisos I, III; art. $6^{\circ}$, caput; art. 196; art. 226, $\S 7^{\circ}$ ).

Leva-se em consideração que a criminalização do aborto tem como consequência a procura por procedimentos inseguros, que quando mal sucedidos - em grande parte das vezes - gera prejuízos à saúde da mulher, inclusive resultando em morte. Desta maneira, a ação pretende que o STF exclua do âmbito de incidência dos artigos 124 e 126 do Código Penal a interrupção da gestação induzida e voluntária realizada nas primeiras 12 semanas de gravidez.

Nos dias 03 e 06 de agosto de 2018 foi realizada audiência pública na Primeira Turma, oportunidade na qual o STF ouviu 51 entidades com experiência e autoridade sobre a matéria. Cada entidade teve o tempo de vinte minutos para exposição, sendo este tempo dividido entre àquelas que tinham mais de um representante.

O Ministério da Saúde, responsável pela elaboração das principais políticas públicas brasileiras na área da saúde, foi a primeira entidade a falar na audiência. Por se tratar de setor do Governo, não se pronunciaram a favor ou contra a descriminalização do aborto. A contribuição foi através da apresentação de dados que poderiam fomentar a discussão. Destacou-se que a redução da mortalidade materna está entre os Objetivos de Desenvolvimento Sustentável da ONU até 2030. No Brasil, o abortamento é a terceira causa de morte materna direta. Além disso, estima-se que são realizados mais de um milhão de abortos induzidos por ano e que uma a cada cinco mulheres já fez um aborto, independente de classe social. São realizadas duzentas e cinquenta hospitalizações por ano para tratamento de abortos inseguros mal sucedidos, além de haver uma morte a cada dois dias pelo mesmo motivo (MINISTÉRIO DA SAÚDE DO BRASIL: 2018; n.p.).

A descriminalização do aborto permite a elaboração de programas e ações pelo governo para assistir mulheres que decidem realizar o procedimento do aborto voluntário e até mesmo, no caso uruguaio, de fornecer as informações que melhor orientem as mulheres antes da decisão de interrupção da gestação. A criminalização não impede sua realização, conforme dados apresentados pelo próprio Ministério da Saúde. Logo, para cumprir o objetivo de reduzir a mortalidade materna, é necessária a elaboração de políticas de amparo para a terceira causa de morte direta: o abortamento.

Sobre o debate em torno do aborto no Brasil, além da discussão judicial cujo expoente é a já referida ADPF 442, o tema também é pauta no legislativo. No sentido oposto, há movimentação para aprovação da PEC 29/2015 do Senado, que propõe alterar o artigo $5^{\circ}$ da Constituição Federal, incluindo que a inviolabilidade do direito à vida é desde a concepção.

A principal consequência desta alteração na Constituição é que o aborto não seria permitido em hipótese alguma, inclusive nas previstas legalmente hoje no Brasil (gravidez decorrente de 
violência sexual, que oferece risco de vida para a mãe ou anencefalia do feto). A mesma alteração da Constituição foi inserida na discussão da PEC 181/2015 da Câmara dos Deputados, que versava sobre licença-maternidade em caso de parto prematuro, ampliando o debate do tema.

\section{Considerações finais}

A experiência uruguaia de descriminalização do aborto ao lado da edição de lei e decreto com sua regulamentação, bem como formulação de políticas públicas que prestam assistência de saúde para as mulheres que decidem realizar o abortamento, demonstra que este caminho é eficaz para redução do número de mortes maternas. No Brasil, contudo, a realidade ainda é outra: o aborto é crime, em regra, sendo permitido apenas em situações específicas.

A criminalização do abortamento voluntário impede a criação de políticas públicas efetivas para assistir a saúde sexual e reprodutiva das mulheres, além de ter como consequência a busca por práticas clandestinas e inseguras para abortar. As condições sanitárias desfavoráveis e a dificuldade de acesso à saúde, bem como o medo que impede as mulheres de procurar ajuda médica, são responsáveis pelo alto número de mortalidade materna no Brasil.

Apesar de ser um país laico, o aborto induzido não é permitido e a justificativa para tanto é de ordem religiosa. As iniciativas legislativas para definir o início da vida e, como consequência, criminalizar o abortamento em quaisquer hipóteses possuem fundamentos estritamente religiosos, não encontrando respaldo na ciência ou no próprio sistema jurídico.

A moralidade imposta pelos parlamentares suplanta os aspectos bioéticos e a mulher passa a ser obrigada a aceitar uma gestação ainda que indesejada, o que reduz sua condição de sujeito de direitos livre para fazer suas escolhas de vida. A criminalização do aborto fere diversos princípios bioéticos e permite com que estejam ainda mais vulneráveis as mulheres que praticam o aborto clandestino, já que na maioria das vezes a busca por este procedimento é feita por mulheres já em situação de vulnerabilidade.

Com base na experiência do Uruguai sobre o tema, afirmamos que é imprescindível que o tema aborto seja tratado de maneira racional e imparcial, livre de juízos de valor. Somente assim é possível a elaboração de políticas públicas efetivas, que assegurem os direitos sexuais e reprodutivos das mulheres brasileiras, e não apenas a edição de normas gerais ou abstratas sobre a questão.

\section{Notas}

1 Procuradora do Município de Pirangi/SP. Mestranda em Direito pela Faculdade de Ciências Humanas e Sociais/FCHS (UNESP-Franca). Especialista em Direito Administrativo pela Pontifícia Universidade Católica de Minas Gerais (PUC Minas). Advogada inscrita na OAB-SP. Bacharel em Direito pela Universidade Federal de Ouro Preto (UFOP).E-mail: deboravaserino@gmail.com

2 Doutora em Direito pela Universidad de Barcelona (2001), com título reconhecido pela Faculdade de Direito da USP. Professora na graduação e pós graduação da Universidade Estadual Paulista Júlio de Mesquita Filho (UNESP). Tem experiência como docente das disciplinas Bioética, Ética, Introdução ao Estudo do Direito, Direito Tributario, com ênfase em Bioética, atuando principalmente nos temas que envolvem os avanços biotecnológicos e suas implicações juridicas, e judicialização da saúde. Membro do Comitê de Ética e Pesquisa da Faculdade de Ciências e Letras de Araraquara (CEP-UNESP) e do Centro de Estudos e Práticas Pedagógicas da UNESP (CENEPP - UNESP). Tutora do grupo de Educação Tutorial 
(PET- Administração Pública/UNESP), vinculado ao MEC-SESu. Ouvidora da Faculdade de Ciências e Letras de Araraquara. Avaliadora do Sistema Nacional de Avaliação da Educação Superior - MEC. E-mail: pmarchetto@fclar.unesp.br

\section{Referências}

BRASIL. Ministério da Saúde. Supremo Tribunal Federal. Audiência Pública na ADPF 442. Disponível em: https://www.youtube.com/watch?v=dugDjoH-PYI. Acesso em: 22 fev. 2019.

Câmara dos Deputados. Proposta de Emenda à Constituição n. ${ }^{\circ} 181$ de 2015. Disponível em: https:// www.camara.leg.br/proposicoesWeb/fichadetramitacao?idProposicao=2075449. Acesso em: 21 fev. 2019.

. Constituição (1988). Constituição da República Federativa do Brasil. Brasília, DF: Senado Federal. . Código Penal. Decreto-Lei n 2.848, de 7 de dezembro de 1940. Brasília, DF: Senado Federal.

. Ministério da Saúde. Portaria ${ }^{\circ} 1.459$ de 24 de junho de 2011. Institui no âmbito do Sistema Único de Saúde - SUS - a Rede Cegonha. Brasília: Ministério da Saúde, 2011.

Ministério da Saúde. Secretaria de Atenção à Saúde. Departamento de Ações Programáticas Estratégicas. Politica de Assistência Integral à Saúde da Mulher: princípios e diretrizes. Brasília: Ministério da Saúde, 2004.

. Senado Federal. Proposta de Emenda à Constituição n. ${ }^{\circ} 29$ de 2015. Disponível em: https://www25. senado.leg.br/web/atividade/materias/-/materia/120152. Acesso em: 21 fev. 2019.

HARGAIN, Geraldo Caetano. Latinoamericana - Enciclopédia Contemporânea da América Latina e do Caribe. Disponível em: http://latinoamericana.wiki.br/verbetes/u/uruguai. Acesso em: 15 fev. 2019.

JOHNSON, Nick; ROCHA, Cecilia; SCHENCK, Marcela. La inserción del Aborto en la Agenda político-pública uruguaya 1985-2013: Un análisis desde el Movimiento Feminista. Cotidiano Mujer, Montevidéu, 2015. Disponível em: http://cotidianomujer.org.uy/sitio/ediciones-de-cotidiano/1177-la-insercion-del-aborto-en-la- -agenda-politico-publica-uruguaya-1985-2013-un-analisis-desde-el-movimiento- -feminista. Acesso em: 15 fev. 2019.

URUGUAI. Decreto n. ${ }^{\circ}$ 375/2012. Regulamentacion de la ley sobre interrupcion voluntaria del embarazo o ley del aborto. Disponível em: https://www.impo.com.uy/bases/decretos/375-2012. Acesso em: 21 fev. 2019.

Ministerio de la Salud Pública. Avances y desafios em interrupción voluntaria del embarazo. Disponível em: https://www.gub.uy/ministerio-salud-publica/comunicacion/noticias/avances-y-desafios-en-interrupcion-voluntaria-del-embarazo. Acesso em: 16 fev. 2019.

Ministerio de la Salud Pública. Embarazos de adolescentes bajaron de 14,2\% em 2016 a 12,7\% em 2017. Disponível em: https://www.gub.uy/ministerio-salud-publica/comunicacion/noticias/embarazos-de-adolescentes-bajaron-de-142-en-2016-127-en-2017. Acesso em: 21 fev. 2019.

Ministerio de la Salud Pública. Fecundidad, mortalidad infantil y materna: tendencias a la baja. Disponível em: https://www.gub.uy/ministerio-salud-publica/comunicacion/noticias/fecundidad-mortalidad-infantil-y-materna-tendencias-la-baja. Acesso em: 18 fev. 2019.

Lei n. ${ }^{\circ}$ 18.987/2012. Ley sobre interrupcion voluntaria del embarazo. Ley del aborto. Disponível em: https://www.impo.com.uy/bases/leyes/18987-2012. Acesso em: 21 fev. 2019. 